\title{
Objective degree of freedom in activity as the factor of professional talent formation
}

T. N. Soboleva ${ }^{1}$

${ }^{1}$ Far Eastern State Transport University

DOI: 10.18255/1996-5648-2021-3-452-463

Research article

Full text in Russian

This article is devoted to the poorly studied problem of the objective degree of freedom in activity as the factor of professional talent formation. The study was carried out on a sample of 108 qualified railway drivers using a professional simulator that allows to simulate three degrees of freedom in activity. On the basis of empirical data it is shown that the degree of freedom in activity is manifested in individual productivity. The structures of professional talent, different in composition and degree of integration, are formed depending on the objective degree of freedom in activity.

Keywords: activity; freedom; normative mode of action; professional talent; subject of activity

\section{INFORMATION ABOUT AUTHORS}

Soboleva, Tatyana N. | E-mail: lzhedunova@mail.ru

Cand. Sc. (Psychology), Associate Professor 


\section{Объективная степень \\ свободы в деятельности \\ как фактор формирования \\ профессиональной одарённости}

\section{Т. Н. Соболева ${ }^{1}$}

${ }^{1}$ Дальневосточный государственный университет путей сообщения

DOI: $10.18255 / 1996-5648-2021-3-452-463$

удк 159.98

Научная статья

Полный текст на русском языке

Статья посвящена малоизученной проблеме объективной степени свободы в деятельности как фрактору фрормирования профессиональной одарённости. Исследование проводилось на выборке из 108 квалифрицированных машинистов железнодорожного транспорта с использованием профессионального тренажера, позволяющего имитировать три степени свободы в деятельности. На основе эмпирических данных показано, что степень свободы в деятельности определяет индивидуальную результативность деятельности. В зависимости от объективной степени свободы в деятельности формируются различные по составу и мере интеграции структуры профессиональной одарённости.

Ключевые слова: деятельность; свобода; нормативный способ действия; профессиональная одарённость; субъект деятельности

\section{ИНФОРМАЦИЯ ОБ АВТОРАХ}

Соболева, Татьяна Николаевна

E-mail: t.n.s.25vivat@mail.ru

Кандидат психологических наук, доцент

Объективная степень свободы в деятельности как фактор формирования профессиональной одарённости представляется малоизученной проблемой. Сложность данной проблемы в психологической науке определяется тем, что нет исследований, которые бы ясно давали конкретное определение свободы в профессиональной деятельности. Эта проблема усложняется еще тем, что нет разработок, которые были бы посвящены выявлению различной степени свободы в профессиональной деятельности. Вместе с этим любая деятельность характеризуется объективной неопределённостью, обусловленной различной степенью сложности тре(с) Соболева Т. Н., 2021

Статья открытого доступа под лицензией CC BY (https://creativecommons.org/licenses/by/4.0/) 
Соболева Т.Н.

бований. Работы К. А. Абульхановой, А. В. Карпова, В. Д. Шадрикова свидетельствуют о том, что требования деятельности способствуют фрормированию системы индивидуальных качеств, способностей и одарённости субъекта при сохранении общего, базового ядра личности [1-3]. Однако вопрос о том, как будут изменяться внутренние условия субъекта, каким образом они будут проявляться, структурироваться под влиянием конкретных требований деятельности, недостаточно изучен, такого материла крайне мало.

Б. М. Теплов в 1941 г. первым обозначил проблему понимания одарённости как качественную. По его мнению, одарённость следует рассматривать как качественно своеобразное сочетание способностей. Современными психологами, к сожалению, не уделяется должного внимания положению Б. М. Теплова и оно практически не разрабатывается [4].

Имеется парадокс: при широчайшем использовании понятия одарённости вопрос о её сущности, конкретном составе и механизмах фрормирования и развития остается открытым. В современной психологической науке одарённость является неоднозначным, наполненным различным содержанием понятием. В. Д. Шадриков, развивая подход к одарённости Б. М. Теплова, определяет её как системное взаимодействие способностей, направленное на получение желательного результата, выступающее как качественное новообразование субъекта деятельности, имеющее индивидуальную меру выраженности и развивающееся в деятельности и жизнедеятельности [4-5].

Учитывая позицию В. Д. Шадрикова [5], опираясь на словарные толкования свободы, а также на теоретические представления С. Л. Рубинштейна о свободе в деятельности [6], мы придерживаемся следующего определения: свобода в профбессиональной деятелъности - это отношение субъекта к объективной неопределённости условий и требований деятельности, которое определяется целями, мотивами, профессионально важными качествами субъекта деятельности и проявляется в выборе адекватного способа действия.

На основе понятия свободы в профессиональной деятельности мы определяем степенъ свободъ в профессионалъной деятелъности - это условия объективной неопределённости требований деятельности, когда субъект имеет возможность реализовать инициативу в аспекте репродуктивной или продуктивной активности, которая определяется его отношением к этой неопределённости и направлена на выбор пригодного способа действия. Выбор способа действия осуществляется субъектом с ориентацией на основные показатели нормативного результата деятельности.

Нами разработана характеристика трёх степеней свободы в профессиональной деятельности, в основе которых лежит нормативно одобренный способ действия. 
Низкая степенъ свободъ в деятельности характеризуется нормативными параметрами деятельности, когда у субъекта знания способов действия согласуются с условиями и требованиями и имеется чёткое представление о нормативных способах действия, прописанных в инструкциях. Задача деятельности для субъекта состоит в поддержании и сохранении нормативных требований. Субъект реализует репродуктивную активность в рамках нормативности и несёт ответственность за соблюдение нормативного способа деятельности.

Средня степенъ свободъ в деятельности характеризуется сочетанием таких нормативных и ненормативных параметров деятельности, когда знания способов действия у субъекта не согласуются с условиями и требованиями, но имеются в распоряжении отдельные нормативные способы, комбинация из которых даёт возможность решить проблему. Основная задача состоит в ликвидации отклонений от нормативности в деятельности. Субъект реализует продуктивную активность. В этом случае его инициативные действия выходят за рамки нормативности и включают элементы творчества. В связи с этим мера ответственности повышается, поскольку имеется риск того, что «свой» способ действия может привести к нарушению требований технической безопасности.

Высокая степенъ свободъ в деятельности характеризуется ненормативными параметрами деятельности, при которых субъекту неизвестен способ действия, поскольку таких ситуаций нет в личном опыте и они не предусмотрены инструкциями, тогда ему приходится открывать новый способ. В этом случае основная задача деятельности состоит в ликвидации ненормативных параметров деятельности. Субъект реализует продуктивную активность, выходящую за рамки нормативности, поскольку его инициативные действия направлены на существенное переструктурирование нормативного способа действия. В этом случае субъект проявляет творческий подход к выполнению своих профессиональных обязанностей, но мера ответственности существенно повышается, поскольку высока цена ошибки.

Мы предполагаем, что объективная степень свободы в деятельности может выступать детерминантой, определяющей формирование качественно-своеобразных структур профессиональной одарённости, которые обеспечивают индивидуальную успешность результата деятельности.

\section{Организация исследования и методы}

В эмпирическом исследовании приняли участие 108 квалифицированных машинистов железнодорожного транспорта, которые были разделены на три группы по 36 человек: первую группу составили машинисты, реализующие поездку на тренажере в условиях низкой степени свободы в деятельности; вторую группу - машинисты, осуществляющие ту же деятельность в условиях средней степени свободы; третью группу - маши- 
Соболева Т.Н.

нисты, осуществляющие ту же деятельность в условиях высокой степени свободы.

Все группы равноценны по следующим критериям: возрасту, образованию, стажу, классу, наставничеству в течение года, экспертности в течение года, участию в выявлении проектно-конструкторских недостатков при эксплуатации новой техники в течение 5 лет, участию в проектно-конструкторских разработках новой техники в течение 5 лет.

Исследование было проведено в три этапа. На первом этапе был осуществлен психологический анализ деятельности машиниста, в результате которого выявлен состав профессиональной одаренности, включающий семь наименований способностей. В таблице 1 представлен перечень способностей и методики их диагностики.

Таблица 1

\section{Состав профессиональной одарённости и методики её оценки}

\begin{tabular}{|c|c|}
\hline $\begin{array}{c}\text { Состав профессиональной } \\
\text { одаренности }\end{array}$ & Методики диагностики \\
\hline $\begin{array}{l}\text { 1. Общие способности коор- } \\
\text { динации движений тела }\end{array}$ & $\begin{array}{l}\text { Компьютерный стабилографический метод с биологически обрат- } \\
\text { ной связью «Стабилан-01» (ЗАО «ОКБ "Ритм"», г. Таганрог): тест } \\
\text { со ступенчатым отклонением в одном направлении с удержанием } \\
\text { позы (разработчик - С. С. Слива и др., 2001) }\end{array}$ \\
\hline $\begin{array}{l}\text { 2. Специальные способности } \\
\text { координации движений тела }\end{array}$ & $\begin{array}{l}\text { Компьютерный стабилографический метод с биологически обрат- } \\
\text { ной связью «Стабилан-01» (ЗАО «ОКБ "Ритм"», г. Таганрог): тест } \\
\text { на оценку запаса устойчивости человека при отклонении вперед - } \\
\text { назад, вправо - влево (разработчик - С. С. Слива и др., 2001) }\end{array}$ \\
\hline $\begin{array}{l}\text { 3. Способности сенсомотор- } \\
\text { ной реакции рук и глаз }\end{array}$ & $\begin{array}{l}\text { Аппаратурная методика оценки времени сложной двигатель- } \\
\text { ной реакции рук и глаз (авторское право принадлежит компании } \\
\text { ОАО «РЖД», ДВГУПС, 2004) }\end{array}$ \\
\hline $\begin{array}{l}\text { 4. Способности переключения } \\
\text { внимания }\end{array}$ & $\begin{array}{l}\text { Аппаратурная методика определения скорости переключения } \\
\text { внимания на красно-черных таблицах Шульте-Платонова (автор- } \\
\text { ское право принадлежит ОАО «РЖД», ДВГУПС, 2004) }\end{array}$ \\
\hline $\begin{array}{l}\text { 5. Способности устойчивости } \\
\text { внимания }\end{array}$ & $\begin{array}{l}\text { Аппаратурная методика определения устойчивости внимания (ав- } \\
\text { торское право принадлежит ОАО «РЖД», ДВГУПС, 2004) }\end{array}$ \\
\hline $\begin{array}{l}\text { 6. Способности мышле- } \\
\text { ния на уровне технического } \\
\text { понимания }\end{array}$ & $\begin{array}{l}\text { Тест «Механика» (разработан Дж. Фланаганом и адаптирован В. } \\
\text { А. Чикер, 2003) }\end{array}$ \\
\hline $\begin{array}{l}\text { 7. Способности мышления } \\
\text { на уровне реконструкции тех- } \\
\text { нического образа }\end{array}$ & $\begin{array}{l}\text { Тест «Сборка» (разработан Дж. Фланаганом и адаптирован В. А. } \\
\text { Чикер, 2003) }\end{array}$ \\
\hline
\end{tabular}

На втором этапе осуществлялась диагностика результата деятельности под влиянием низкой, средней и высокой степени свободы на компью- 
терных тренажерных комплексах «Торвест-Видео» в моделях: «ВЛС-80», «Ярмак» (разработаны и изготовленные в ЗАО научно-производственном центре «СПЕКТР» г. Екатеринбурга, 2003). Исследование испытуемых проводилось индивидуально.

Согласно выявленным трём способам действия в условиях низкой, средней и высокой степени свободы, были разработаны и задавались конкретные технические параметры на компьютерных тренажерных комплексах, представленных в таблице 2.

Таблица 2

Технические характеристики низкой, средней и высокой степени свободы В деятельности на компьютерном тренажерном комплексе ${ }^{1}$

\begin{tabular}{|c|c|c|c|}
\hline Критерии & $\begin{array}{c}\text { Низкая степень } \\
\text { свободы } \\
\text { в деятельности }\end{array}$ & $\begin{array}{c}\text { Средняя } \\
\text { степень свободы } \\
\text { в деятельности }\end{array}$ & $\begin{array}{c}\text { Высокая степень } \\
\text { свободы } \\
\text { в деятельности }\end{array}$ \\
\hline $\begin{array}{l}\text { 1. Профиль пути } \\
24 \text { км: спуски } \\
\text { и подъемы, кривые }\end{array}$ & $\begin{array}{l}\text { Уклоны от 0,0 до } 4 \text { \%о } \\
\text { Нет кривых }\end{array}$ & $\begin{array}{ll}\text { Уклоны от 0,0 до } 7 \% 0 \\
\text { Кривая } & \text { большо- } \\
\text { го радиуса } & \end{array}$ & $\begin{array}{l}\text { Уклоны от 0,0 до } 12 \text { \%о } \\
\text { Кривая малого радиуса }\end{array}$ \\
\hline $\begin{array}{l}\text { 2. Условия } \\
\text { деятельности }\end{array}$ & $\begin{array}{l}\text { Встречный, порыви- } \\
\text { стый ветер до } 12 \text { м/с } \\
\text { на участке протяжён- } \\
\text { ностью } 300 \text { м }\end{array}$ & $\begin{array}{l}\text { Плановые ремонт- } \\
\text { ные работы на кон- } \\
\text { кретном участке пути } \\
\text { протяжённостью } 300 \text { м }\end{array}$ & $\begin{array}{l}\text { Неожиданное посте- } \\
\text { пенное прибывание } \\
\text { сточных вод и погруже- } \\
\text { ние рельсов под воду } \\
\text { на участке протяжён- } \\
\text { ностью } 300 \text { м }\end{array}$ \\
\hline 3. Способдеятельности & $\begin{array}{l}\text { Нормативный способ } \\
\text { действия }\end{array}$ & $\begin{array}{l}\text { Комбинирование нор- } \\
\text { мативных способов } \\
\text { действия }\end{array}$ & $\begin{array}{l}\text { Переструктурирова- } \\
\text { ние нормативных спо- } \\
\text { собов действия }\end{array}$ \\
\hline $\begin{array}{l}\text { 4. Тип ситуации } \\
\text { неисправности }\end{array}$ & $\begin{array}{l}\text { При ведении элек- } \\
\text { тропоезда загорается } \\
\text { сигнальная лампа ЗБ } \\
\text { (зарядка батарей), нет } \\
\text { зарядки аккумулятор- } \\
\text { ных батарей }\end{array}$ & $\begin{array}{l}\text { При ведении элек- } \\
\text { тропоезда прекрати- } \\
\text { лась работа вспомога- } \\
\text { тельных машин }\end{array}$ & $\begin{array}{l}\text { При ведении электро- } \\
\text { поезда происходит } \\
\text { отключение главного } \\
\text { выключателя в обеих } \\
\text { секциях }\end{array}$ \\
\hline
\end{tabular}

На mретъем этапе осуществлялась диагностика структуры одарённости, (см. описание первого этапа). Индивидуальное обследование квалифицированных машинистов включало 7 методик и проводилось сразу после выполнения задания на тренажере.

${ }^{1}$ Ситуации неисправности под влиянием высокой степени свободы в деятельности подбирались на основе малой вероятности характерных причин неисправности и редкости их встречаемости в работе машиниста; \%о - знак, обозначающий промилле, уклон железнодорожного пути. Тип локомотива и подвижного состава задавался одинаковый для трёх степеней свободы. 
Соболева Т.Н.

Математическая обработка данных проводилась с использованием коэффициента ранговой корреляции Спирмена, поскольку подавляющее большинство данных, полученных в эмпирическом исследовании, нормально не распределено. Различия между тремя независимыми выборками в показателях результативности деятельности на тренажере определялись с помощью непараметрического критерия Крускала - Уолеса. При обработке данных использовался пакет статистических программ - SPSS Statistica версия 17.0. Наряду с этим применялись оригинальные разработки В. Д. Шадрикова, А. В. Карпова, предложенные для оценки характера структурной организации системы в рамках структурно-функционального подхода, метод оценки индекса когерентности (интегрированности) системы и метод «экспресс- $\chi^{2}$ » для определения гомогенности-гетерогенности матриц интеркорреляций.

\section{Результаты и их обсуждение}

Рассмотрим результативность деятельности в условиях различной степени свободы. Из приведенных данных в таблице 3 следует, что успешность деятельности по преимущественному числу показателей отчетливо различается в группах, выполняющих деятельность в условиях различной степени свободы. Однако мера изменения уровня управления автотормозами в зависимости от различной степени свободы в деятельности близка к статистически значимой $(H=5,686)$.

Когда субъект оказывается в условиях повышенной неопределённости, тогда нормативный способ действия сдерживает и сковывает его продуктивную активность. Это начинает проявляться в снижении показателей результата деятельности. Чем выше степень свободы субъекта, тем ниже результативность продолжительности поездки и времени устранения ситуации неисправности, тем больше случаев нарушения безопасности движения поезда, но выше качественный уровень управления автотормозами. В ходе выполнения деятельности испытуемый осознаёт, что нормативного способа действия недостаточно и, более того, такой способ оказывается вообще непригодным к решению нестандартной проблемы; тогда субъект принимает решение и пытается разработать пригодный, новый, способ действия. В результате степень субъективной оценки нормативного способа действия снижается, а степень субъективной оценки скомбинированного способа и нового способа действия повышается с ростом степени свободы субъекта в деятельности (табл. 3).

Полученные индивидуальные показатели результата деятельности позволяют нам рассматривать низкую, среднюю и высокую степень свободы как объективные причины различий успешности в деятельности. Учитывая, что результативность есть функция сформированной системы профессиональной одарённости, можно сказать, что различная степень 
Объективная степень свободы в деятельности ...

свободы в деятельности может рассматриваться как объективная внешняя детерминанта формирования профессиональной одарённости.

Таблица 3

\section{Различия показателей результата деятельности в зависимости от степени свободы субъекта²}

\begin{tabular}{|c|c|c|c|c|c|c|c|c|}
\hline & $\begin{array}{l}\text { ттепень свободы } \\
\text { в деятельности }\end{array}$ & $\begin{array}{r}\text { Низкая } \\
\text { сво } \\
\text { в деяте }\end{array}$ & $\begin{array}{l}\text { тепень } \\
\text { оды } \\
\text { ьности }\end{array}$ & $\begin{array}{r}\text { Cре } \\
\text { степень } \\
\text { в деяте }\end{array}$ & $\begin{array}{l}\text { няя } \\
\text { вободы }\end{array}$ & $\begin{array}{r}\text { Высокая } \\
\text { своб } \\
\text { в деяте }\end{array}$ & $\begin{array}{l}\text { степень } \\
\text { оды } \\
\text { юьности }\end{array}$ & Нэмп - \\
\hline $\begin{array}{l}\text { Показ } \\
\text { деятє }\end{array}$ & $\begin{array}{l}\text { атели результата } \\
\text { льности на компью- }\end{array}$ & $\begin{array}{r}\text { Первая } \\
=\end{array}$ & $\begin{array}{l}\text { оуппа, n } \\
6\end{array}$ & $\begin{array}{r}\text { Втс } \\
\text { группа }\end{array}$ & $n=36$ & $\begin{array}{r}\text { Tрє } \\
\text { группа }\end{array}$ & $\begin{array}{l}\text { Тья } \\
n=36\end{array}$ & $\begin{array}{l}\text { крускала - } \\
\text { Уоллеса }\end{array}$ \\
\hline терно & м тренажёре & $\mathrm{X}_{\mathrm{cp}}$ & $\sigma$ & $\mathrm{Xcp}_{\mathrm{c}}$ & $\sigma$ & $\mathrm{X}_{\mathrm{cp}}$ & $\sigma$ & \\
\hline $\begin{array}{l}\text { 1. Пр } \\
\text { поезг }\end{array}$ & $\begin{array}{l}\text { одолжительность } \\
\text { ки, с }\end{array}$ & 2635 & 481,59 & 4909,94 & 1442,35 & 6122,80 & 1211,81 & 67,821 \\
\hline $\begin{array}{l}\text { 2. Вр } \\
\text { ситуа }\end{array}$ & $\begin{array}{l}\text { емя устранения } \\
\text { ции неисправности, с }\end{array}$ & 304,13 & 145,17 & 482,80 & 178,97 & 648,36 & 175,48 & 46,885 \\
\hline $\begin{array}{l}\text { 3. Кол } \\
\text { наруь } \\
\text { движе }\end{array}$ & $\begin{array}{l}\text { пиество } \\
\text { јений безопасности } \\
\text { 2ния поезда }\end{array}$ & 2,02 & 1,61 & 2,63 & 2,39 & 4,08 & 2,89 & 10,365 \\
\hline $\begin{array}{l}\text { 4. Урс } \\
\text { автот }\end{array}$ & $\begin{array}{l}\text { вень управления } \\
\text { ормозами, баллы }\end{array}$ & 2,58 & 0,55 & 2,44 & 0,69 & 2,77 & 0,48 & 5,686 \\
\hline 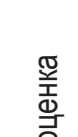 & $\begin{array}{l}\text { нормативного } \\
\text { способа действия, } \\
\text { баллы }\end{array}$ & 23,44 & 3,64 & 18,86 & 4,18 & 14,66 & 3,84 & 50,411 \\
\hline 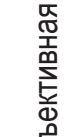 & $\begin{array}{l}\text { скомбинированного } \\
\text { способа действия, } \\
\text { баллы }\end{array}$ & 19,63 & 3,09 & 22,80 & 4,83 & 20,38 & 3,77 & 10,245 \\
\hline ত্ত & $\begin{array}{l}\text { нового способа } \\
\text { действия, баллы }\end{array}$ & 16,08 & 3,90 & 16,08 & 7,24 & 25,36 & 2,68 & 48,437 \\
\hline
\end{tabular}

ИКС - индекс когерентности системы; ОСКдТ - общие способности координации движений тела; ССКдТ - специальные способности координации движений тела; ССРР - способности сенсомоторной реакции руки и глаз; СПВ - способности переключения внимания; СУВ - способности устойчивости внимания; СМТП - способности мышления на уровне технического понимания; СМРТО - способности мышления на уровне реконструкции технических образов. Затемнённый кружок указывает на базо-

${ }^{2}$ Прилечание. Жирным шрифртом выделены эмпирические значения $H_{\text {эмп }}-$ Крускала Уоллеса, попавшие в зону значимости. Критерий Крускала - Уоллеса: $H_{к p}=5,991$ для $\mathrm{p} \leqslant 0,05$; $H_{\text {кр }}=9,210$ для $\mathrm{p} \leqslant 0,01$ при $v=2$. 
вую способность. Широкая стрелка от способности указывает на то, что она является ведущей в системе одарённости.

На рисунке 1 видно, что фрормируются различные структуры профессиональной одарённости в зависимости от свободы выбора способа действия субъектом. Самый высокий индекс когерентности (интеграции) системы одарённости сорормирован в условиях высокой степени свободы в деятельности, когда субъектом разрабатывается новый способ действия. С небольшим отрывом следует система одарённости, сорормированная в условиях средней степени свободы в деятельности. Самый низкий индекс когерентности системы одарённости получен в условиях низкой степени свободы в деятельности, когда субъектом воспроизводится и реализуется нормативный способ действия. Кроме того, в условиях низкой степени свободы в деятельности из системы одарённости выпали общие способности координации движений тела.
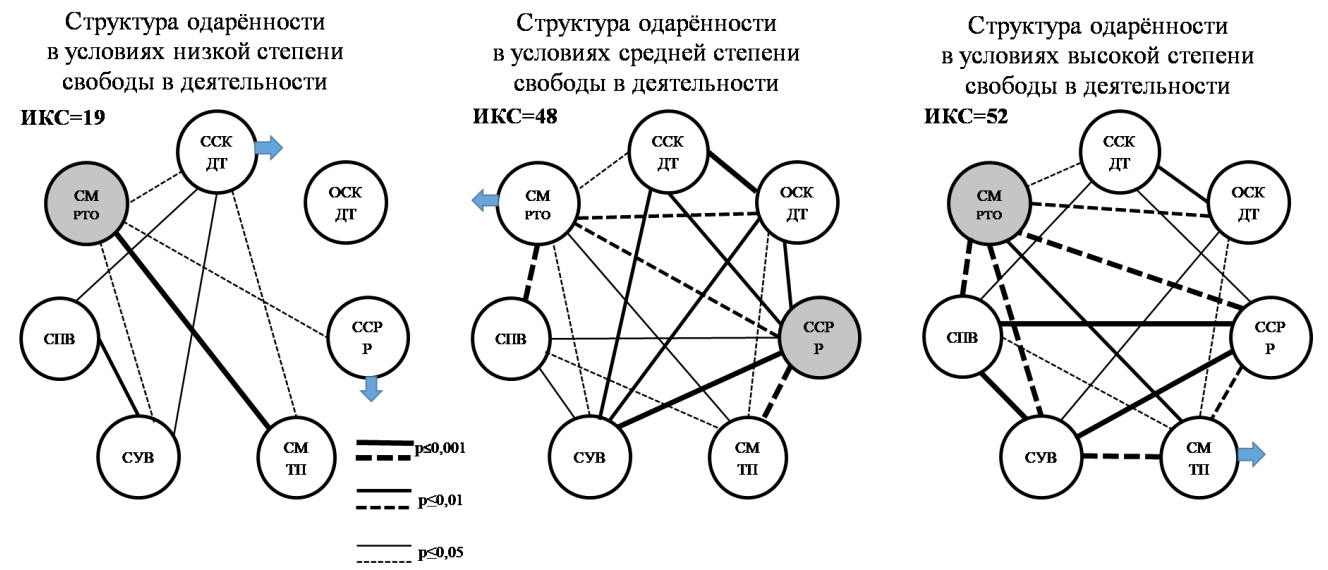

Рисунок 1. Структуры профессиональной одарённости в условиях различной степени свободы в деятельности

Применение метода «экспресс- $\chi^{2}$ » позволило установить абсолютную гетерогенность трёх структур профессиональной одарённости: между низкой и средней степенью свободы $\chi_{\text {эмп }}^{2}=-0,10$; между низкой и высокой степенью свободы $\chi_{\text {эмп }}^{2}=0,32$; между средней и высокой степенью свободы $\chi_{\text {эмп }}^{2}=0,46$. Полученные коэффрициенты не имеют статистической значимости на уровнях достоверности: $p=0,05, \chi_{\text {крит }}^{2}=0,78 ; p=0,01, \chi_{\text {крит }}^{2}=0,94$ для $\mathrm{n}=7$.

Структура связей в системе профессиональной одарённости с точки зрения её представленности в отношении условий низкой, средней и высокой степени свободы имеет следующие характерные особенности:

1) индивидуальные положительные связи в структурах; 
2) индивидуальные отрицательные связи в структурах;

3) сходные положительные связи, но различной меры тесноты;

4) сходные отрицательные связи, но различной меры тесноты (рис. 1).

Таким образом, различен характер корреляционных связей в структурах одарённости в условиях различной степени свободы в деятельности.

Наряду с положительными корреляционными связями в структуре одарённости имеются и отрицательные корреляционные связи (рис. 1). Это можно объяснить тем, что в структуре одарённости есть способности с высокой мерой проявления на фроне достаточного (оптимального) уровня проявления других способностей в условиях различной степени свободы в деятельности. Оптимальная мера проявления способностей оказывается неодинаковой в условиях низкой, средней и высокой степени свободы, что проявляется в образовании отрицательных связей. Степень свободы в деятельности определяет как линейный, так и нелинейный характер взаимодействия между способностями в системе одарённости, что обусловлено линейными и нелинейными изменениями параметров технической системы, управляемой субъектом. Данные описания согласуются с работами Дж. Найт, С. А. Bennet, E. C. Wortz, A. C. McTee, W. F. Swartz о линейных и нелинейных изменениях в системе взаимодействия оператора и технического объекта [7-9]. Нелинейность взаимодействия способностей в системе профессиональной одарённости растёт с повышением степени свободы в деятельности. Можно отметить, что система профессиональной одарённости формируется и перестраивается под влиянием различной степени свободы в деятельности.

В структурах профессиональной одарённости имеются различные базовые способности, которые играют интегрирующую роль, а также могут способствовать установлению компенсаторных фрункциональных связей между способностями в структуре. Однако в условиях низкой и высокой степени свободы в деятельности одни и те же способности мышления на уровне реконструкции технического образа проявились в качестве базовых. Возможно, субъект проявляет творческий подход в способах работы не только в условиях высокой степени свободы, но и условиях низкой степени свободы в деятельности, что приводит к актуализации способностей мышления на уровне реконструкции технического образа, обеспечивающих мысленную реконструкцию определённого участка схемы электроцепи, где произошла проблема (сбой, замыкание и т. п.). Данные базовые способности интегрируют всю структуру способностей для решения технической неисправности и приводят к взаимодействию способностей и других психологических качеств по принципу нелинейности. В структурах профессиональной одарённости имеются различные ведущие способности, которые непосредственно оказывают влияние на показа- 
Соболева Т.Н.

тели результата деятельности и субъективной оценки способов действия в условиях различной степени свободы (рис. 1).

\section{Выводы}

Неотъемлемой сутью фрормирования профессиональной одарённости выступает включённость её в функциональную систему профрессиональной деятельности. Степень объективной свободы в профессиональной деятельности выступает в качестве одного из важнейшего фактора фрормирования профессиональной одарённости.

В условиях низкой, средней и высокой степени свободы в деятельности формируются различные структуры профессиональной одарённости. Эти различия проявляются: в неодинаковом составе способностей; в различных корреляционных связях между способностями; в индивидуальном индексе когерентности системы одарённости; смене базовых и ведущих способностей. Полученные данные доказывают, что чем выше степень свободы в деятельности, тем более целостной, с более высокой мерой интеграции формируется система профессиональной одарённости. Функциональные возможности профессиональной одарённости определяются объективной степенью свободы в деятельности.

Степень свободы субъекта по-разному влияет на показатели результата деятельности. При этом каждый показатель результата деятельности и субъективной оценки способа действия реализуется своей подсистемой способностей. Установлено, что чем выше объективная неопределённость условий и требований деятельности, тем большей свободой выбора способа действия обладает субъект и тем больше ответственности он берёт на себя в принятии решений.

В целом отметим, что свобода в профессиональной деятельности выступает как проявление субъектности, характеризующейся свободой творчества в деятельности. В личной свободе проявляется индивидуальный подход субъекта к требованиям деятельности, его репродуктивная или продуктивная активность в выборе способа действия. Одним из механизмов реализации свободного выбора субъектом выступает профессиональная одарённость.

\section{Ссылки}

1. Абульханова К. А. Психология и сознание личности (Проблемы методологии, теории и исследования реальной личности): Избранные психологические труды. М.: Московский психолого-социальный институт; Воронеж: МОДЭК, 1999. 224 с.

2. Карпов А. В. Психология деятельности: Качественная гетерогения организации: монография: в 5 т. М.: Российская академия образования, 2015. Т. 5. 470 с.

3. Шадриков В. Д. Психология деятельности человека. М.: Институт психологии РАН, 2013. 464 с. 
4. Теплов Б. М. Избранные труды: в 2 т. Т. 1: Способности и одаренность. М.: Педагогика, 1985. 328 с.

5. Шадриков В. Д. Способности и одарённость человека. М.: Институт психологии РАН, 2019. 274 с.

6. Рубинштейн С. Л. Человек и мир. Проблемы общей психологии. М.: Педагогика, 1973. 385 с.

7. Найт Дж. Ручное управление и слежение. Человеческий фактор: в 6 т. Т. 1: Эргономика - комплексная научно-техническая дисциплина: пер. с англ. / Ж. Кристенсен, Д. Мейстер [и др.]. М.: Мир, 1991. 485 с.

8. Bennet C. A. Sampled-data tracking: Sampling of the operator's output // Journal of Experimental Psychology. 1956. № 51. P. 429-438.

9. Wortz E. C., McTee A. C., Swartz W. F. Effects of control-display displacement functions on pursuit and compensatory tracking // Aerospace Medicine. 1965. № 36. P. 1042-1047. 